\title{
Impact of the use of different skinfold calipers for the analysis of the body composition
}

\author{
Edilson Serpeloni Cyrino ${ }^{1}$, Alexandre Hideki Okano ${ }^{1,2}$, Maria Fátima Glaner ${ }^{1,3}$, Marcelo Romanzini ${ }^{1}$, Luís \\ Alberto Gobbo ${ }^{1}$, Altair Makoski ${ }^{1}$, Nelson Bruna ${ }^{1}$, Juliana Cordeiro de Melo ${ }^{1}$ and Gustavo Neri Tassi ${ }^{1}$
}

\begin{abstract}
With the advances in the studies of body composition, it has been observed that several factors can interfere with the estimates of relative body fat using the skinfold thicknesses method. Therefore, the purpose of this study was to investigate the impact of the use of different skinfold calipers for the analysis of body composition by skinfold thicknesses measurements. Two hundred and fifty nine male subjects ( $23.3 \pm 2.9$ years) took part of the study. Nine skinfold thicknesses were measured (abdominal, subscapular, suprailiac, triceps, biceps, midaxillary, chest, medial calf, and thigh) using the Lange (USA) and the Cescorf (Brazil) calipers with accuracy of 1.0 and $0.1 \mathrm{~mm}$, respectively. Significant differences were found in the comparison between the two calipers on all the investigated skinfold thicknesses (1.8 to $31.0 \%)$ with highest values obtained by the Lange caliper $(\mathrm{p}<0.01)$. When these values were applied to four different predictive equations, developed by different researchers, the body fat estimate was significantly modified ( $p<0.01$ ), resulting in differences of 5.2 to $6.9 \%$. Results indicate that the use of different skinfold calipers may maximize the errors of estimation produced by different predictive equations used for the analysis of body composition.
\end{abstract}

Key words: Skinfold thicknesses. Body composition. Calipers. Predictive equations.

1. Grupo de Estudo e Pesquisa em Metabolismo, Nutrição e Exercício. Centro de Educação Física e Desportos. Universidade Estadual de Londrina.

2. Universidade Estadual de Campinas.

3. Universidade Católica de Brasília.

Received in 8/9/02

$2^{\text {nd }}$ version received in $4 / 1 / 03$

Accepted in 18/5/03

Correspondance address:

Grupo de Estudo e Pesquisa em Metabolismo, Nutrição e Exercício

Centro de Educação Física e Desportos

Universidade Estadual de Londrina

Rod. Celso Garcia Cid, km 380, Campus Universitário

86051-990 - Londrina, PR - Brasil

E-mail: emcyrino@uel.br

\section{INTRODUCTION}

Among the main methods to assess body composition, the skinfold thickness method (ST) stands out, as it is easy to apply, is of low operational cost, provides validity and reliability.

ST method is considered to be doubly indirect, as it is structured from the assumptions of hydrostatic weigh (HW), which, in spite of being an indirect method, has been considered a golden standard for the study of body composition in humans. Thus, just like HW method, ST method allows assessment of both, fat and lean body mass, as body composition assessment is performed from body density estimates generated from specific or general regression equations.

It is believed that in healthy adults, one third of total fat is found in subcutaneous area ${ }^{1}$. Furthermore, there seems to be a good relationship between fat found in subcutaneous deposits and body density?

As the sites where subcutaneous fat lay are not uniform, one must measure skinfold thickness at different anatomic sites from different body segments (upper limbs, lower limbs, trunk), in order to have a more clear, overall and regional perception of fat distribution ${ }^{2,3}$. Thus, the anatomic sites to be used for estimating body density and, therefore, the relative body fat, depend on the adopted predictive equation ${ }^{4}$.

Many factors may affect the measurement of skinfold thickness, among which the type of caliper to be used, as this instrument should provide accurate, reliable measures.

Thus, among the many calipers available in the market, Lange (USA) and Harpenden (UK) are considered the best ones, as there are scientific studies on the reliability of measurements done with these instruments, by comparing relative body fat estimates calculated from the use of each one of them with results obtained from the HW method ${ }^{5,6}$. Furthermore, Whitehead ${ }^{7}$ compared five types of caliper and found that Lange (LNG) and Harpenden (HRP) had the best design for accuracy.

In Brazil, Cescorf (CCF) caliper, manufactured in the country, is widely accepted by users of ST method and in- 
vestigators in the field of body composition over the past two decades. CCF's design and mechanics are similar to HRP's, with a constant pressure for any range of its jaws of approximately $10 \mathrm{~g} / \mathrm{mm}^{2}$, measure unit of $0.1 \mathrm{~mm}$ and contact surface of $90 \mathrm{~mm}^{2}$, according to the manufacturer. However, there is little information on this caliper, particularly if compared to other similar equipment highly considered in the literature.

Based on the presented information, the purpose of this study was to compare skinfold thickness assessed by LNG and $\mathrm{CCF}$ calipers, and then analyze the impact of possible differences found on relative body fat estimates from different predictive equations.

\section{METHODOLOGY}

\section{Subjects}

Two hundred and fifty-nine apparently healthy males $(23.3 \pm 2.9$ years of age $)$ took part in this study. They were all informed on the purpose of the investigation and the procedures they would be submitted to, and signed an informed consent form.

\section{Methods}

Body mass was assessed with the use of a digital scale, brand Urano (model PS 180A), with unit measure of 0.1 $\mathrm{kg}$, whereas stature has been determined with the use of a wood stature measurer, with unite measure of $0.1 \mathrm{~cm}$, in accordance to procedures described by Gordon et al. ${ }^{8}$. From the body mass and stature measurements, body mass index (BMI) was calculated, by means of body mass/ $/$ stature $^{2}$, ration, being body mass expressed in kilos $(\mathrm{kg})$ and stature in meters $(\mathrm{m})$.

To assess subcutaneous fat, the skinfold thickness of the following sites were measured: suprailiac (SI), subscapular (SE), triceps (TR), biceps (BI), medial calf (MC), thigh $(\mathrm{TH})$, and chest $(\mathrm{CH})$, in accordance with procedures described by Harrison et al. ${ }^{3}$, and abdominal $(\mathrm{AB})$, established parallel to the longitudinal body axis, approximately $2 \mathrm{~cm}$ from the lateral edge of the navel; midaxillary (MA), obliquely measured following the direction of intercostal arches. These measurements were performed by a single evaluator, with test-retest coefficient of over 0.95 for each anatomic site, and technical measurement error of $\pm 0.8 \mathrm{~mm}$ and \pm 1.0 $\mathrm{mm}$, at the most, for Cescorf and Lange calipers, respectively. It is worth stressing that, whenever necessary, measures taken with Lange caliper were adjusted by linear interpolation of $0.5 \mathrm{~mm}$.
All measurements were taken on a rotation basis, and repeated three times with each caliper, and were recorded by a registrar. Median of the three measurements from each anatomic site was adopted as value of reference. At the end of each of three sequences, the evaluator changed calipers. The measurement sequence for the study was: $A B$, SI, SE, TR, BI, CH, MC, TH e MA. Measurements were made on the right side of the body, and the subjects wore just a bathing suit.

From the skinfold thickness, body density was calculated using the predictive equations proposed by Durnin \& Womersley ${ }^{9}$, Jackson \& Pollock ${ }^{10}$, and Petroski ${ }^{11}$ (table 1). Relative body fat was estimated from the equations proposed by Siri ${ }^{12}$ or Brozek et al. ${ }^{13}$, according to the information these authors originally presented.

Data was handled according to descriptive procedures, and all comparisons between calipers were performed with the use of Student $t$-test for dependent samples. Information was processed by software Statistica ${ }^{\mathrm{TM}}$.

\section{RESULTS}

Description of the subjects' physical features is presented in table 2.

Thickness values of the nine measured skinfold by LNG and CCF calipers are presented in table 3. Significant differences were found for all skinfolds upon comparison between the two calipers $(p<0.01)$, with LNG presenting higher values. Midaxillary was the skinfold thickness of smaller difference between the two calipers, whereas biceps presented the highest variation $(1.8$ and $31 \%$, respectively).

Table 4 presents values for relative body fat estimated by four body density predictive equations.

Differences in relative body fat estimates from the use of LNG and CCF calipers were significant in all analyzed

\begin{tabular}{|c|c|c|}
\hline \multicolumn{3}{|c|}{$\begin{array}{c}\text { TABLE } 1 \\
\text { Predictive equations used to calculate body density }\end{array}$} \\
\hline Investigators & Year & Predictive equation \\
\hline Durnin \& Womersley ${ }^{9}$ & 1974 & $\mathrm{Bd}=1,1765-0,0744 \log _{10}\left(\sum 4 S T 1\right)$ \\
\hline J ackson \& Pollock ${ }^{10}$ & 1978 & $\begin{array}{c}\mathrm{Bd}=1,109380-0,0008267\left(\sum 3 \mathrm{ST}\right) \\
+0,0000016\left(\sum 3 \mathrm{ST}\right)^{2}-0,0002574(\mathrm{Ag})\end{array}$ \\
\hline J ackson \& Pollock ${ }^{10}$ & 1978 & $\begin{array}{c}\mathrm{Bd}=1,1120-0,00043499\left(\sum 7 \mathrm{ST}\right) \\
+0,00000055\left(\sum 7 \mathrm{ST}\right)^{2}-0,00028826(\mathrm{Ag})\end{array}$ \\
\hline Petroski ${ }^{11}$ & 1995 & $\begin{array}{l}\mathrm{Bd}=1,10726862-0,00081201\left(\sum 4 \mathrm{ST} 2\right) \\
+0,00000212\left(\sum 4 \mathrm{ST}\right)^{2}-0,00041761(\mathrm{Ag})\end{array}$ \\
\hline
\end{tabular}


TABLE 2

General features of the sample subjects

\begin{tabular}{lrrrr}
\hline \multicolumn{1}{c}{ Variables } & \multicolumn{3}{c}{$\begin{array}{c}\text { Mean } \\
\text { Standard } \\
\text { deviation }\end{array}$} \\
& & & & \\
Age (years) & 23.3 & 2.9 & 18.0 & 30.0 \\
Body mass (kg) & 73.2 & 9.7 & 53.3 & 102.0 \\
Stature (cm) & 178.0 & 6.2 & 159.0 & 190.5 \\
BMI (kg/m²) & 23.1 & 2.6 & 17.9 & 31.2 \\
\hline
\end{tabular}

equations $(p<0.01)$, ranging between 5.2 and $6.9 \%$, being the highest values determined by LNG.

\section{DISCUSSION}

The importance of investigating skinfold measurement differences among the various calipers, and the impact of such information for the study of body composition started to be demonstrated particularly from the 80 s onward. Thus, findings similar to those of our investigation have been reported in other studies, showing that LNG caliper presented higher values when compared to others ${ }^{14-16}$.

Statistic differences observed from the comparison of thickness from each of the nine investigated skinfolds $(p<$ 0.01 ) suggest that possible differences among calipers are likely related to different accuracy levels of the utilized tools $(0.1$ to $1.0 \mathrm{~mm})$, differences in model and mechanics of the tools.

Thus, the contact surface of LNG's jaws is of $30 \mathrm{~mm}^{2}$, whereas CCF's is of $90 \mathrm{~mm}^{2}$, under constant and somewhat similar pressure applied (approximately $10 \mathrm{~g} / \mathrm{mm}^{2}$ ). As pressure reflects the relationship between power and contact surface, a three-fold difference in the contact surface, under similar pressure makes the strength exerted to open the legs of caliper CCF to be three times higher than the one applied to LNG.

Likewise, some investigators have reported that HRP, whose design and mechanics are apparently similar to CCF's, requires three-fold the power to open its legs, due to differences in the contact surface, causing higher compression of the fat tissue ${ }^{14,17}$. This was seen by Gruber et al. ${ }^{14}$, who noted that for the same skinfold, HRP caliper takes one second longer to complete the movement (reading). Therefore, it is likely that in their study the difference of the two calipers in surface area is one of the reasons for higher skinfold thickness values measured by LNG.

These differences are lower than the ones found by Gruber et al. ${ }^{14}$, when comparing LNG and HRP calipers. These authors noted that HRP values are $11.8 \%$ lower than LNG's.

Likewise, Lohman et al. ${ }^{17}$ observed that fat percentage assessed with the use of caliper HRP were $11 \%$ to $17 \%$ lower

\begin{tabular}{|c|c|c|}
\hline \multicolumn{3}{|c|}{$\begin{array}{c}\text { TABLE } 3 \\
\text { Skinfold thickness ( } \mathrm{mm} \text { ) and correlation } \\
\text { between calipers Lange e Cescorf }\end{array}$} \\
\hline Skinfold (mm) & Lange & Cescorf \\
\hline$A B$ & $18.9 \pm 7.6^{*}$ & $18.0 \pm 7.9$ \\
\hline SI & $15.0 \pm 7.3^{*}$ & $14.7 \pm 7.2$ \\
\hline SE & $14.5 \pm 6.1^{*}$ & $14.1 \pm 5.9$ \\
\hline $\mathrm{TR}$ & $12.7 \pm 5.3^{*}$ & $11.3 \pm 5.0$ \\
\hline $\mathrm{BI}$ & $5.5 \pm 2.4^{*}$ & $4.2 \pm 2.1$ \\
\hline $\mathrm{CH}$ & $9.9 \pm 5.2 *$ & $9.6 \pm 4.9$ \\
\hline $\mathrm{MC}$ & $9.8 \pm 4.3^{*}$ & $8.9 \pm 4.0$ \\
\hline MA & $11.2 \pm 6.2^{*}$ & $11.0 \pm 5.7$ \\
\hline $\mathrm{TH}$ & $15.1 \pm 5.8^{*}$ & $13.8 \pm 5.5$ \\
\hline \multicolumn{3}{|l|}{$* p<0.01$ vs. Cescorf. } \\
\hline \multicolumn{3}{|c|}{$\begin{array}{c}\text { TABLE } 4 \\
\text { Comparison among relative body fat figures estimated } \\
\text { by different predictive equations, developed from } \\
\text { the use of calipers Lange and Cescorf }\end{array}$} \\
\hline Equations & Lange & Cescorf \\
\hline (1) & $19.6 \pm 5.7^{*}$ & $18.5 \pm 5.9$ \\
\hline (2) & $12.4 \pm 5.1^{*}$ & $11.6 \pm 5.0$ \\
\hline (3) & $13.1 \pm 5.5^{*}$ & $12.4 \pm 5.4$ \\
\hline (4) & $16.2 \pm 5.4^{*}$ & $15.4 \pm 5.3$ \\
\hline
\end{tabular}

$* \mathrm{p}<0,01$ vs. Cescorf

Note: Predictive equations: (1) Durnin \& Womersley ${ }^{9}$; (2) J ackson \& Pollock ${ }^{10}-3 S T$; (3) J ackson \& Pollock ${ }^{10}-7 \mathrm{ST}$; (4) Petroski ${ }^{11}$.

than LNG figures, according to the predictive equation analyzed.

Differences in the magnitude of fat prediction from different calipers, between our study and Lohman's et al. ${ }^{17}$ and Gruber's et al. ${ }^{14}$ show that, even though CCF and HRP calipers have similar design and mechanics, differences in accuracy ( 0.1 and $0.2 \mathrm{~mm}$, respectively) cannot be ignored when analyzing results generated from these instruments. It is to be mentioned that there is no available information in the literature about comparison between these calipers.

In the sample studied, differences in estimates from the use of two different calipers (LNG and CCF) amount to approximately 500 to $800 \mathrm{~g}$ more of fat, and therefore less lean body mass, when measurement in made with LNG compared to $\mathrm{CCF}$.

In spite of the understanding that body composition is by itself complicated, we believe the information gathered by the application of measures taken from different calipers in various regression equations developed to estimated body density may help reducing possible sources of measurement error involving ST $\operatorname{method}^{17}$, as this body 
composition assessment method, being considered doubly indirect, presents a series of limitations related to the method of reference (hydrostatic weigh) ${ }^{4}$.

Due to biologic variability caused particularly by differences among individuals in the relationship between subcutaneous and total body fat, at least in theory, accuracy of the equations that use ST measurements to estimate body density and relative body fat is of $0.0075 \mathrm{~g} / \mathrm{cm}^{3}$ and 3.3 percentage points, respectively ${ }^{18}$. Therefore, predictive errors of $\leq 3,5$ relative fat percentage points or $0.0080 \mathrm{~g} / \mathrm{cm}^{3}$ for equations involving ST may be considered acceptable, as a proportion of the errors are related to the reference method $^{19}$. Thus, taking, for instance, Petroski's equation ${ }^{11}$, developed from LNG caliper, presented standard estimate error (SEE) for body density of $0.0075 \mathrm{~g} / \mathrm{cm}^{3}$ or 3.3 relative fat percentage points over its development. According to criteria proposed by Lohman ${ }^{20}$, this model could be rated between good and very good. On the other hand, if CCF caliper was used, error of the relative body fat estimate would be added of an extra 1.2 percentage points, leading this model to be rated only as fair.

It is to be mentioned that the four examined equations, originally proposed from LNG caliper, had their results 5.2\% to $6.5 \%$ underestimated by CCF caliper.

\section{CONCLUSIONS}

The outcomes of this study show that body fat estimates may be significantly affected by the type of caliper utilized, which seems to be directly related to the instrument's accuracy, design (contact surface) and mechanics.

Therefore, relative body fat estimates from CCF caliper tends to be 5.2 to $6.9 \%$ lower than from LNG caliper, according to the predictive equations examined in this study. These differences imply higher body fat values, and therefore lower lean mass values when LNG caliper is used.

As determining and validating predictive equations to calculate body density is done from the use of a particular caliper, differences caused by the use of different types of caliper tend to increase estimate error from the used equation, thus compromising results achieved by ST method.

Therefore, selecting the caliper to be used for measuring body fat should be done according to the predictive equations chosen to be employed on a particular population.

It is to be stressed that monitoring of possible changes in body composition over time may also be compromised if different calipers are used at different moments.

To close, it seems interesting the development of correction equations among the different calipers for the various anatomic sites measured, to minimize differences among them. Furthermore, other studies on calipers, focusing the different design, mechanics and accuracy, may add to a more appropriate use of ST method.

All the authors declared there is not any potential conflict of interests regarding this article.

\section{REFERENCES}

1. Lohman TG. Applicability of body composition techniques and constants for children and youth. Exerc Sport Sci Rev 1986;14:325-57.

2. Martin AD, Ross WD, Drinkwater DT, Clarys JP. Prediction of body fat by skinfold caliper: assumptions and cadaver evidence. Int J Obes Relat Metab Disord 1985;9:31-9.

3. Harrison GG, Buskirk ER, Carter LJE, Johston FE, Lohman TG, Pollock ML, et al. Skinfold thicknesses and measurement technique. In: Lohman TG, Roche AF, Martorell R, editors. Anthropometric standardization reference manual. Champaign: Human Kinetics Books, 1988; 55-70.

4. Heyward VH, Stolarczyk LM. Avaliação da composição corporal aplicada. São Paulo: Manole, 2000.

5. Hayes PA, Sowood PJ, Belyavin A, Cohen JB, Smith FW. Subcutaneous fat thickness measured by magnetic resonance imaging, ultrasound, and calipers. Med Sci Sports Exerc 1988;20:303-9.

6. Sloan AW, Shapiro MA. Comparison of skinfold measurements with three standard calipers. Hum Biol 1972;44:29-36.

7. Whitehead JR. A study of measurement variation among different skinfold calipers. Br J Phys Educ 1990;7:10-4.

8. Gordon CC, Chumlea WC, Roche AF. Stature, recumbent length, and weight. In: Lohman TG, Roche AF, Martorell R, editors. Anthropometric standardization reference manual. Champaign: Human Kinetics Books, 1988;3-8.

9. Durnin JVGA, Womersley J. Body fat assessed from total body density and its estimation from skinfold thickness: measurements on 481 men and women aged from 16 to 72 years. Br J Nutr 1974;32:77-97.

10. Jackson AS, Pollock ML. Generalized equations for predicting body density of men. Br J Nutr 1978;40:497-504.

11. Petroski EL. Desenvolvimento e validação de equações generalizadas para a estimativa da densidade corporal em adultos. Tese de Doutorado, Centro de Educação Física e Desportos, Universidade Federal de Santa Maria, 1995.

12. Siri WE. Body composition from fluid spaces and density: analysis of methods. In: Brozek J, Henschel A, editors. Techniques for measuring body composition. Washington: National Academy of Science, 1961; 22344.

13. Brozek J, Grande F, Anderson JT, Keys A. Densitometric analysis of body composition: revision of some quantitative assumption. Ann NY Acad Sci 1963;110:113-40.

14. Gruber JJ, Pollock ML, Graves JE, Colvin AB, Braith RW. Comparison of Harpenden and Lange caliper in predicting body composition. Res Q Exerc Sport 1990;61:184-90.

15. Hawkins JD. An analysis of selected skinfold measuring instruments. J Health Phys Educ Rec Dance 1983;54:25-7.

16. Zando KA, Robertson RJ. The validity and reliability of the Cramer Skyndex caliper in the estimation of percent body fat. J Athletic Training 1987;22:23-5.

17. Lohman TG, Pollock ML, Slaughter MH, Brandon LJ, Boileau RA. Methodological factors and the prediction of body fat in female athletes. Med Sci Sports Exerc 1984;16:92-6.

18. Lohman TG. Skinfolds and body density and their relation to body fatness: a review. Hum Biol 1981;53:181-225.

19. Jackson AS. Research design and analysis of data procedures for predicting body density. Med Sci Sports Exerc 1984;16:616-22.

20. Lohman TG. Advances in body composition assessment. Current issues in exercise science series. Monograph No. 3. Champaign: Human Kinetics Books, 1992. 